\title{
Pharmaceutical Quality, Team Science, and Education Themes: Observations and Commentary on a Remarkable AAPS PharmSciTech Theme Issue
}

\author{
Ajaz S. Hussain, ${ }^{1,2}$ Kenneth Morris, ${ }^{2,3}$ and Vadim J. Gurvich ${ }^{1,4,5}$ (I)
}

Received 17 February 2021; accepted 19 February 2021; published online 4 March 2021

\section{INTRODUCTION}

The AAPS PharmSciTech Theme Issue entitled "Team Science and Education for Pharmaceuticals - the NIPTE Model" curates nineteen papers (1-19) listed in Table I and written before and amidst the COVID-19 pandemic. Another manuscript, currently in the editorial process, is expected to be the final paper in the Theme Issue. It will review the evolution of the NIPTE education certificate program over the past three years and describes a shift from a didactic, lecture-based curriculum to a more interactive, flipped, casebased program developed through backward design. Of the nineteen papers we discuss here, one is focused on assessing the impact of NIPTE (1), and two describe contemporary challenges confronting the sector and were contributed by us, the editors of Theme Issue $(12,18)$. Sixteen papers describe research methodology and outcomes for questions posed in a request for proposals by the US FDA (identified by shaded rows in Table I). Others describe research projects that were self-sponsored locally or funded by a corporate grant or contract. Three are open access papers $(1,12,18)$, two $(1,12)$ per AAPS PharmSciTech consideration and the third (18) by default per the United Nations open science recommendation to help address the COVID-19 challenge.

Guest Editors: Ajaz S. Hussain, Kenneth Morris, and Vadim J. Gurvich

\footnotetext{
${ }^{1}$ The National Institute for Pharmaceutical Technology and Education (NIPTE), Inc., Minneapolis, Minnesota 55414, USA.

2 Arnold and Marie Schwartz College of Pharmacy and Health Sciences, Long Island University, Brooklyn Campus, Brooklyn, New York 11201, USA.

${ }^{3}$ Lachman Institute for Pharmaceutical Analysis, Long Island University, Brooklyn Campus, Brooklyn, New York 11201, USA.

${ }^{4}$ Institute for Therapeutics Discovery and Development, College of Pharmacy, University of Minnesota, Minneapolis, 55414, Minnesota, USA.

${ }^{5}$ To whom correspondence should be addressed. (e-mail: vadimg@umn.edu)
}

The term team science broadly refers to collaborative research at the National Institute for Pharmaceutical Technology and Education (NIPTE). Note the emphasis on "for" in naming NIPTE is to signify its virtual eco-system for doing things voluntarily. In this context, team science is to go beyond individual and additive efforts to voluntarily engaging and committing to collaborative research to address a multidisciplinary question or solve a particular problem.

In and among the sixteen technical papers that make the Theme Issue, what did we observe and what sense did we make of the state of pharmaceutical quality, team science, and education? In this paper, which closes the Theme Issue, we answer these questions and place them in the context of assuring the availability of adequate quantities and quality of pharmaceuticals amidst the COVID-19 pandemic and beyond 2020. We intend to help readers of AAPS PharmSciTech to appreciate the nineteen papers individually and the Theme Issue holistically. We also record our appreciation to the AAPS PharmSciTech and its Editor for providing the space and support for the theme issue.

\section{THE CONTEXT: BACKGROUND INFORMATION}

The shared yearning to generate optimal recognition and funding for research and education in pharmaceutics, industrial pharmacy, and pharmaceutical engineering is a driver that brings together a core group of faculty members at NIPTE member institutions. It is also the glue that maintains the viability of this virtual eco-system. Beyond this core group, other faculty members engage when funding becomes available. NIPTE collaborates with the US FDA to channel this yearning towards improving science-based regulatory policies and practices.

The following background information provides a context for the readers to appreciate the narrative we generate from our observations to describe opportunities for and challenges in aligning and integrating academic research and education with the evolving legislative and regulatory policy 
Table I. What Theme, a Central Topic, or Message We Observed Within the Narratives of the Articles?

Ref. Title of paper that contributed to the Theme Issue

(1) The Impact of the National Institute for Pharmaceutical Technology and Education on Academic Research

(2) Using Manufacturing Design Space Concepts for Stability Risk Assessment-Gabapentin NIPTE/FDA Case Study.

(3) Particle Size Distribution Equivalency as Novel Predictors for Bioequivalence.

(4) The Sensitivity of In Vitro Permeation Tests to Chemical Penetration Enhancer Concentration Changes in Fentanyl Transdermal Delivery Systems.

(5) A Simplified Geometric Model to Predict Nasal Spray Deposition in Children and Adults.

(6) Sensitive Determination of Fentanyl in Low-Volume Serum Samples by LC-MS/MS.

(7) Impact of Natural Variations in Freeze-Drying Parameters on Product Temperature History: Application of Quasi Steady-State Heat and Mass Transfer and Simple Statistics

(8) Scale-Up and In-line Monitoring During Continuous Melt Extrusion of an Amorphous Solid Dispersion

(9) Influence of Formulation Factors on the Aerosol Performance and Stability of Lysozyme Powders: A Systematic Approach.

(10) New Insights on Solid-State Changes in the Levothyroxine Sodium Pentahydrate during Dehydration and its Relationship to Chemical Instability.

(11) Pediatric Formulations: Knowledge Gaps Limiting the Expedited Preclinical to Clinical Translation in Children

(12) Pharmaceutical "New Prior Knowledge": Twenty-First Century Assurance of Therapeutic Equivalence

(13) Feedforward and Feedback Control of a Pharmaceutical Coating Process. Lesson Learnt from Recall of Valsartan and Other Angiotensin II Receptor Blocker Drugs Containing NDMA and NDEA Impurities

(14)

(15) Predictive and Accelerated Formulation Design Using Synchrotron Methods

(16) Decision Support for Excipient Risk Assessment in Pharmaceutical Manufacturing

(17) Determination of Rate and Extent of Scopolamine Release from Transderm Scōp ${ }^{\circledR}$ Transdermal Drug Delivery Systems in Healthy Human Adults.

(18) In and Beyond COVID-19: US Academic Pharmaceutical Science and Engineering Community Must Engage to Meet Critical National Needs

(19) Development and Validation of Sample Preparation and an HPLC Analytical Method for Dissolution Testing in Fed-State Simulated Gastric Fluid-Illustrating Its Application for Ibuprofen and Ketoconazole Immediate-Release Tablets. Missing funding information.

trends and industry practices. We conclude this paper and the Theme Issue with a commentary on the state of pharmaceutical quality, team science, and education and some considerations for "maturing" of team science at NIPTE.

\section{Art, Science, Powder Technology, Good Pharmaceutical Manufacturing, and COVID-19}

Egyptian tablets date back to antiquity, so what more do we need to know about making pharmaceutical tablets in the twenty-first century? Yes, powder technology is as old as humankind; it is still an art form in many areas-the journey from art to science is the challenge that the FDA's Process Analytical Technology Initiative confronted (20).

Just fifteen years ago, the need for a public system to foster a competitive eco-system for research and education in pharmaceutical science, technology, and engineering was not self-evident (21). Perhaps, this need is still under a shadow that needs illumination.

The funding (for 2006-2016) of an Engineering Research Center for science-based development of structured organic particle-based products and their manufacturing processes, CSOPS, by the National Science Foundation was indeed a significant breakthrough (22). It laid a solid academic foundation for a system for pharmaceutical engineering research and education.

In December 2016, another milestone was the enactment of the 21st Century Cures Act. A section in this Act, "Domestic Manufacturing and Export Efficiency," authorized the FDA to fund continuous pharmaceutical manufacturing research. A few months before and then amidst the COVID19 pandemic, proposals to amend the 21st Century Cures Act transpired. For example, the "National Centers of Excellence in Continuous Pharmaceutical Manufacturing Act of 2020" (23) and other proposals (e.g., H.R.6670-Prescription for American Drug Independence Act of 2020 discussed in (18)) are now awaiting a political consensus.

What impact can NIPTE have on the evolving legislative proposals and how will emerging legislation impact NIPTE are important questions related to the concept of team science that NIPTE has been promoting for many years (24). The pending legislative efforts are critical parts of a long-overdue solution to correct pharmaceutical science and engineering neglect. Today, these juxtapose with the "warp speed" mode of action to deal with the virus-directed public health emergency of COVID-19.

\section{Lessons in Scientific Public-Private Partnerships and Consor- tia and Warp Speed}

The Product Quality Research Institute (PQRI), created in 1998, was an initial effort at the US FDA to formalize and structure its collaborative search for efficient methods of ensuring unchanged product quality and performance during scale-up of pharmaceutical dosage forms (25). Today PQRI is an established organization, and it continues to generate and share information among its regulatory and industry stakeholders (26). However, the search for efficient methods of ensuring unchanged product quality and performance for switching from batch to continuous manufacturing is an 
important topic that needs to be appreciated, particularly in the context of a public health emergency and "warp speed."

NIPTE was established in 2005 to generate a critical mass of academic resources dedicated to fundamental research and education in pharmaceutical product development and manufacturing. Today, it develops and disseminates new knowledge in a voluntary, not-for-profit, educational ecosystem with very modest funding (1). NIPTE, in its core faculty leadership, was a door opener; today, it is one among fifty-three (see Table II below) partners that collaborate with CDER FDA to identify science and fill science gaps in drug development (26).

Over the years, other research funding sources were established, for example, under Generic Drug User Fee Amendments (predominantly for the development of bioequivalence assessment methodologies) and the 21st Century Cures Act (for continuous pharmaceutical manufacturing). NIPTE member institutions have often competed individually and sometimes collectively to address these challenges; still, the need to bridge chemistry, manufacturing, and controls with bioequivalence remains needs attention (24).

\section{Reliable Supply of Required Quantities and Quality A} National Security Need

Before the COVID-19 pandemic, the pharmaceutical supply chain's reliability was wanting, and affordable medicine delivery was under severe strain. Although a growing recognition that a reliable supply of quality pharmaceuticals is a national security need exists (18), finding a consensus solution to secure uninterrupted supply remains elusive. The challenge at hand is complex, perhaps akin to redesigning systems, including corporate and public research and development, manufacturing, regulatory, and education.

\section{NIPTE Is a Part of the Solution}

Indeed, NIPTE is a unique collaboration within the context of US academic expertise in pharmaceutical science, technology, and engineering. Is this specialty valuable, appreciated, or still needed? The exponentially increasing complexity and scale of challenges we confront demands team science. For NIPTE, to fulfill its promise to be a significant part of the solution, its team science must be more than an additive effect, and the value of its outcomes must be evident.

The continued ability of NIPTE to contribute, we posit, relates strongly to its relative maturity (and recognition of the value of maturity) in the larger eco-system of scientific publicprivate partnerships with federal agencies (e.g., as in Table II). What is "maturity"? Here, we pose this question to place it in our awareness while we describe our observations. We comment on characteristics relevant to assessing the maturity of pharmaceutical socio-technical systems at the conclusion.

\section{OBSERVATIONS: TEAM SCIENCE AND EDUCATION FOR PHARMACEUTICALS-THE NIPTE MODEL}

Several papers in the Theme Issue offer an opportunity to observe how research is and can be organized,
Table II. Current CDER/FDA's Scientific Public-Private Partnerships and Consortia (26). Note the Table Highlights Only a Few of the Fifty-Three Partnerships Directly Relevant to This Discussion

1. Alcohol Clinical Trials Initiative (ACTIVE)

2. Accelerating Medicines Partnership (AMP)

6. Biomarkers Consortium (BC)

9. Critical Path for Parkinson's (CPP)

16. Dissolution Working Group

33. National Institute for Innovation in Manufacturing Biopharmaceuticals (NIIMBL)

34. National Institute for Pharmaceutical Technology and Education (NIPTE)

38. Product Quality Research Institute (PQRI)

39. The Patient-Reported Outcome Consortium (PRO)

45. RX-360

53. Worldwide Innovative Networking (WIN) Consortium

communicated, and conducted. We noted the article entitled "Using Manufacturing Design Space Concepts for Stability Risk Assessment-Gabapentin NIPTE/FDA Case Study" (2) with interest. It describes one aspect of a larger study conceived conducted in response to an FDA request for proposal by a team from across nine universities that worked collaboratively with industrial and governmental scientists (see the Acknowledgments section of the paper). The references cited in this paper provide a partial list of other related publications.

The paper develops a methodology to describe the mapping of causal, predictive relationships between manufacturing-related stress and the stability of "model drug" gabapentin (a drug approved by the FDA in 1993). It posits gabapentin as a "model" drug prone to (solid-state) structural disorder under mechanical stress, enhancing susceptibility to stability failures. Implicit in this inquiry, we observe, is a reminder of "unknown unknowns"; that is, sometimes, the process of regulatory approval does not account for important "failure modes."

Some readers may not immediately appreciate that the project generated over fifteen peer-reviewed research papers and seven doctoral dissertations, partially or wholly, based on project data. It supported about ten graduate students and about the same number of post-doc and research scientists (20) - indeed, a valuable academic contribution. In looking past these valuable scholarly contributions, others would be interested in knowing what impact this project would have on improving regulatory policy and industry practices. Here, we observe a gap in NIPTE and FDA processes on research to policy to practice translation. We will return later in the paper as participants (in the process) to comment on ways to fill gaps we note.

Solid-State, Material Science, and Predictable Stability and Therapeutic Outcomes

In a broader context of the gabapentin paper (2), we note the report "New Insights on Solid-State Changes in the Levothyroxine Sodium Pentahydrate during Dehydration and its Relationship to Chemical Instability" (10). This investigator-initiated paper builds on the theme of variance 
in solid-state characteristics and their causal links to chemical degradation and product susceptibility to (reoccurring) stability failures. It and several other papers in the Theme Issue relate to two articles we contribute as participants in the process, one on "New Prior Knowledge" (12) and a call to the US academic pharmaceutical science and engineering community to engage in meeting critical national needs (18). Hence, we will discuss these in our commentary.

The need to link the development of drug substances, their products, and their manufacturing process to patient safety (in the QbD paradigm) was a conclusion of the paper entitled "Lesson Learnt from Recall of Valsartan and Other Angiotensin II Receptor Blocker Drugs Containing NDMA and NDEA Impurities" (14).

Several contributions in the Theme Issue remind us of the stubborn gaps in pharmaceutical solid-state and material science. For example, the papers entitled "Decision Support for Excipient Risk Assessment in Pharmaceutical Manufacturing" (16) remind us of the complex behavior of excipients, which poses challenges in assessment when designing a formulation or evaluating regulatory submissions. It outlies an Excipient Risk Assessment System utilizing an experiential knowledge base. The quality risk assessment ideally occurs in the context of clinical safety and effectiveness. Pediatric therapeutics is a topic that must remind us of gaps in knowledge we continue to tolerate.

Beyond optimal decisions on excipients in pediatric formulations, the paper entitled "Pediatric Formulations: Knowledge Gaps Limiting the Expedited Preclinical to Clinical Translation in Children" describes gaps in assessing risk in pediatric clinical outcomes and toxicity. It also outlines the prevailing uncertainties in current assessment systems and ontogenic physiological similarities (11).

In striving for knowledge and risk management over a product's life cycle, we observe the need to be aware of and surface or make apparent uncertainties to prioritize research across multiple partnerships $(27,28)$. For example, a system approach to research problem definition and prioritization to mitigate risk would need to evolve a process to cut across, and perhaps beyond, the listed Scientific Public-Private Partnerships and Consortia in Table II.

\section{Particulate Dosage Forms and Therapeutic Equivalence}

The theme issue included two FDA-sponsored research papers, one on the equivalency of particle size distributions (case of subcutaneous injection dosage forms) (3) and the other on the prediction of nasal spray deposition in children and adults (5). Approval of particulate dosage forms, particularly those of locally acting drugs such as nasal and inhalation products, is a complex process and remains a long-standing challenge.

We note that assessing therapeutic equivalence via "weight of evidence" considerations can be challenging in the pre-market phase. After approval, challenges can continue to occur to create chaos in the lack of assurance of quality and supply reliability (12). Here, our choice of words, complexity and chaotic, as descriptors of the obstacles is measured; we elaborate on why later in the context of a system approach to regulatory research, policy, and practice prioritization.

\section{Failure Modes, Natural Variations, and Measurement Uncertainty}

Identifying "failure modes" (and effects analysis) in a process and a product is the first step to preventing harm. Papers in the theme issue related to adhesive transdermal systems $(4,6,17)$, in part, sought to improve measurements needed to evaluate important performance and quality attributes of these delivery systems. These papers reminded us of the need to pay attention to patient-related failure modes. In and of itself, adhesiveness (which is also in the name we give to these products) is critical to safety, efficacy, quality attributes, and suboptimal adhesive resulting in loss of life (29). The path to correcting, improving, updating regulatory policy to mitigate harm due to patient-related failure modes can be long and winding (30).

The paper entitled "Impact of Natural Variations in Freeze-Drying Parameters on Product Temperature History: Application of Quasi Steady-State Heat and Mass Transfer and Simple Statistics guide process development" (7) outlies a procedure for efficient freeze-drying process design and finding the edge of failure and avoiding the edge of collapse without undue extension of the process. We note with interest this paper's relevance beyond the freeze-drying process because all processes exhibit natural variation. We deliberated on why it (natural variation or common cause variation) is not acknowledged explicitly in other methods and research contributions.

The natural variation, patient-related failure mode, and measurement uncertainty describe the themes of this subsection. We noted the paper (19) on developing an HPLC analytical method for dissolution testing in fed-state simulated gastric fluid in this broader context to observe the relevance of considering and accounting for the differences in pre-market R\&D and post-approval life cycle of quality control dissolution testing. This paper preludes another article on "Similarity of dissolution profiles from biorelevant media" published in another journal; in it, the authors observed-“favorable inter-day repeatability (83 of 88 comparisons were similar), favorable inter-analyst repeatability (19 of 21 comparisons were similar), and favorable interlaboratory reproducibility (10 of 14 comparisons were similar) of dissolution profiles" (31). These observations give us reason to pause to reflect on how might these observations of reproducibility and repeatability and are relevant in the context of education, training, and assurance of data integrity for requests of waiver in vivo bioequivalence studies and routine quality control testing, effective Out-of-Specification investigations, corrective and preventive actions, and continual improvement, particularly in the context of a globalized supply chain and disruption in FDA's ability to inspect facilities.

\section{Pharmaceutical Engineering, Pharmaceutical Science, and Therapeutic Equivalence}

Amid the chaos and uncertainty precipitated by the COVID-19 pandemic, we remain hopeful and have reason to celebrate progress in pharmaceutical engineering of continuous manufacturing. Many faculty members in NIPTE member institutions have successfully advanced technologies and 
engineering platforms for continuous pharmaceutical manufacturing, at C-COPs and other universities, such as those who contributed papers $(8,13)$ to the Theme Issue. We also note the article contributing to developing methodologies for predictive and accelerated formulation design and development (15).

Over more than a decade, NIPTE has nurtured an ecosystem to align and integrate research in the fields of pharmaceutics, pharmaceutical manufacturing, pharmaceutical engineering, and physical pharmacy (collectively called "pharmaceutical technology") with the needs of the FDA (1). We posit that NIPTE must now leverage team science to advance progress in "Pharmaceutical Engineering Science of Therapeutic Equivalence." To do so, it must strengthen the timber and consistency of its voice amidst the political noise in public funding decisions for research and education are enacted.

\section{Why Did We Observe What We Observed?}

In writing this paper, we were conscious of motivated observations and limits to their objectivity for reasons such as "conflict of interests." Conscious awareness and writing of this report at the end of the tenure at NIPTE of two of us were the safeguards to maintain objectivity. To the extent feasible, we note and distinguish our observations of, from the commentary on, the themes (see Table III) in this Theme Issue. In Table I, we enclose our comments in parentheses. We elaborate on these and other comments in the following section.

\section{COMMENTARY: MATURING PHARMACEUTICAL SOCIO-TECHNICAL SYSTEMS}

Today, we seek to engineer our processes, products, and systems. The maturity of socio-technical systems is in the harmonious maturity of its parts. We must appreciate and pay attention to maturing both the technologies and the population of professionals, all members of our communities of knowledge and practice. We cannot underestimate the challenge we confront to correct years and layers of disharmony in developing our technologies and ourselves (professionals).
Some readers who had remained committed to and continued this journey from before PQRI or NIPTE existed may still remember the "scandal" in a rush to approve generic drugs. It ushered in the Office of Pharmaceutical Science in CDER, FDA. A crisis or a scandal is often the basis for advancing laws and creating layers of legacy practices and assumptions that get habituated and embedded in our subconscious, so the techniques are applied but no longer consciously chosen. Without this awareness, "never let a serious crisis go to waste" is the preferred strategy, and it is a temptation. We must simultaneously resist this temptation and be strategic. We must strengthen the timber and improve the harmony of our voice.

In this section, we offer a few suggestions. To assess our recommendations, particularly by new members of our pharmaceutical knowledge community, listen to the words' voices in Table IV capture. These voices are passionate commitment to confront the challenges at hand. Let's begin with the end in mind.

\section{"Fail and Fix to Predict and Prevent"}

Before the COVID-19 pandemic, NIPTE had already initiated engagement with policymakers on the concept of "New Prior Knowledge" (12). Today and in the foreseeable future, the urgent need is to prevent critical drug shortages for treating COVID-19 patients and other essential medicines to treat other acute and chronic conditions. Significant progress has been made listing essential drugs and mapping their supply chain to predict and prevent disruptions (35). In 2020, NIPTE advanced rapid response proposals for integrated manufacturing in the USA, i.e., sourcing raw materials in the USA to manufacture drug substances and drug products for both critical injectable drugs and solid dosage forms (18). The challenge at hand is monumental, complex, and in parts chaotic.

Certainly, continuous manufacturing is part of the solution. It is not and cannot be the only solution. The journey ahead is best described as "chaos to continual Improvement" by averting the 2-3 sigma barrier imposed on new drug applications and breaking the 2-3 sigma barrier for products currently on the market. Herein is the opportunity to expand engagement both within and outside NIPTE.

Table III. The Themes We Observed in This Theme Issue

Themes and observations

1 Theme: Solid-State, Material Science, and Predictable Stability and Therapeutic Outcomes. Observation: A tendency to be satisfied with a scholarly contribution, necessary but not sufficient

2 Particulate Dosage Forms and Therapeutic Equivalence. Assessing therapeutic equivalence via "weight of evidence" can be challenging in the pre-market phase. After approval, challenges can continue as a reoccurring failure and CGMP violations (create chaos in the lack of quality and supply reliability (12)).

3 Natural Variations, Failure Modes, and Measurement Uncertainty. Note: Accounting of natural variation and failure modes remain in need of attention. The path to correcting, improving, updating regulatory policy to mitigate harm due to patient-related failure modes can be long and winding.

4 Pharmaceutical Engineering, Pharmaceutical Science, and Therapeutic Equivalence. Progress in pharmaceutical engineering is necessary but not sufficient. (NIPTE must now leverage team science to advance progress in "Pharmaceutical Engineering Science of Therapeutic Equivalence." To do so, it must strengthen the timber and consistency of its voice amidst the political noise in public funding decisions for research and education are enacted.) 
Table IV. Voices that Remind Us of the Challenge at Hand Not to Scare But to Encourage

\begin{tabular}{lc}
\hline "Don't use and Don't Tell." & $\begin{array}{l}\text { Uttered by manufacturing a major pharma corporation at } \\
\text { the FDA Science Board meeting on 16 November 2001 (32) }\end{array}$ \\
\hline "If I Don't Look, there is No Problem." & $\begin{array}{c}\text { Words of quality recorded at a major biopharmaceutical company } \\
\text { as an awakening to break the 2-3 sigma barrier (33, 34) }\end{array}$ \\
$\begin{array}{l}\text { A yearning in a proposal outlined at the 2020 NIPTE Research Conference, } \\
\text { we must confront both the urgent and long-standing challenges amidst } \\
\text { and beyond the COVID-19 pandemic (35) }\end{array}$ \\
\hline
\end{tabular}

Fixing habitual failing is part of the comprehensive stabilizing solution in need of NIPTE leadership in the context of a "third leg of the stool."

\section{A Case of Dissolving Habitual Failing}

Here, for example, the theme "Natural Variations, Failure Modes, and Measurement Uncertainty" is a useful reminder. NIPTE accepting the challenge in an investigatorinitiated manner (not waiting for a request for proposal) confronting the real-world challenge of recurring dissolution test failures can be a basis to inform and appreciate the legacy challenges of under or unaccounted for natural variance in method development and validation in $\mathrm{R} \& \mathrm{D}$ for formulation similarity assessment, setting regulatory specification in the context of an overall control strategy.

That is, break the sectoral habit of treating dissolution testing as a black box and empowering professionals with knowledge on how to justify reasonable controls. Be a voice to support resisting and ending the legacy practice of procrustean (regulatory and compendial) acceptance criteria or limits, often after phase III clinical trials or "pivotal" bio study in case of generic drug development. For the NIPTE community's consideration, the 2020 Conference presentation "Industry Policy-NIPTE" discussed a case of generic metoprolol succinate ER product system dissolution failures as a remainder of "common cause" system-wide challenge (36).

Valid measurement systems with a known and benchmarked error rate are necessary for the proper contexts-R\&D and lot-lot testing. Our measurement technology for solid-state attributes of raw and in-process materials has advanced significantly in the past two decades. However, the implementation of the new measurement technologies lags in practice. The generics sector, a major segment of the industry, will need assistance to be current in their control strategy to provide the assurance patients need and expect to experience the real-world equivalent therapeutic outcome claimed on product labels.

\section{Unlocking the Door to a "Weight of Evidence" Destination}

The pressure on the FDA to approve applications keeps increasing. The nation is precariously dependent on the imported supply of generics drugs and active pharmaceutical ingredients. Surely, most will agree that the COVID-19 pandemic is disrupting supply chains and adding to the preexisting challenge.
Before the COVID-19 pandemic, major parts of the sector struggled to approach pharmaceutical development and complexity systematically. The built-in "file first and figure it out later" business incentives in the law is a powerful force that easily overshadows the power in knowledge. Perhaps, in part, the remedy is at the legislative level. However, a legislative remedy without follow-through based on science is not a viable option.

Inadequate rigor and sufficiency of controls in submitted applications (NDA and ANDA) to the FDA suggest ongoing product development via multiple review cycles, which can pose many challenges to approval and in the postapproval phase. As noted above, over the past several years, significant research funding has been available under the Generic Drug User Fee Amendments Regulatory Science initiative, focusing on developing bioequivalence assessment methods. There is no doubt that a valid bioequivalence assessment methodology is certainly necessary. It is also essential to remember that bioequivalence assessment, when needed, is one of four parts of the system that is supposed to assure therapeutic equivalence in the pre-market phase.

Assurance of lot-to-lot therapeutic equivalence demands knowing failure modes and controlling critical quality attributes in the post-approval phase and over a product's life cycle. We observe an imbalance in need of attention, specifically, to pharmaceutical equivalence and CGMP compared to bioequivalence assessment, typically a one-time assessment pre-approval and occasionally post-approval for certain SUPAC Level 3 changes. Given this background, a delegation of NIPTE faculty members visited FDA in 2016 to, among other things, share ideas on a "CMC Risk Classification System," and later also submitted these formally to the designated FDA Docket $(27,28)$.

NIPTE progressed its "New Prior Knowledge" (12) proposal focusing on solid-state, material science, and measurement uncertainty challenges are the locks on the door leading to a path from the "pivotal bio" station to a "weight of evidence" destination. It seeks to maintain a high level of assurance in generic drugs' therapeutic equivalence, which is essential to keep an optimal balance between patient satisfaction and the public health objectives in promoting generic medicines. The NPK paper illustrated prevailing challenges using real-world case examples and placed the FDA statistics on submissions and approval of ANDA in the context of market chaos while explaining the patient-level consequence of quality failures. Case examples of the erosion of confidence in "therapeutic equivalence" of generic drugs (e.g., when color and shape changes) and also brand products 
were illustrated in the massive backlash in France and other countries to an "improved" formulation of levothyroxine.

\section{Removing the Hurdles in Research to Policy to Practice}

The need to pay attention to "patient-related failure modes" is urgent-a confidence gap prevails in the safety, efficacy, and quality of pediatric formulations (11). The path to correcting, improving, updating regulatory policy can be long and winding (30). Then, implementation in practice often needs enforcement actions, which can be challenging. NIPTE must strengthen the timber and consistency of its voice to contribute ways to accelerating the science to policy to practice journey.

\section{Amidst All Challenges, There Are Many Opportunities to Serve the Nation}

Today, we have reason to celebrate the many members in the NIPTE institutions and broadly, individually and as a team, contributing to advancing technologies and engineering platforms for continuous pharmaceutical manufacturing at $\mathrm{C}$ COPs and other universities. We recommend NIPTE to build on this momentum to promote "Engineering Science of Therapeutic Equivalence." Collectively NIPTE has expertise in parts that are needed to constitute "Engineering Science of Therapeutic Equivalence." It must be a system that can predict and confirm therapeutic equivalence to justify the least burdensome post-approval changes. Superior to legacy consensus "defaults" (e.g., 10× scale-up factor, three batches, and subjective risk classification for post-approval changes) established by the previous SUPAC paradigm.

\section{Concluding Our Observations and Commentary}

In concluding our observations and commentary on a remarkable AAPS PharmSciTech Theme Issue, we return to the importance of committing to team science as a basis to do more. Particularly in the prevailing chaos and uncertainty, doing more is credibly informing the legislative and regulatory systems on problems and solution priorities to secure a reliable supply of expertise, technology, and resources to ensure uninterrupted pharmaceuticals' availability, quantity, and quality that fellow citizens need. To do so, we must overcome the acquired "immunity to change" and increase the Order of Consciousness-two concepts in the theory of constructive development of adult development. These concepts can benefit pharmaceutical professionals and mature systems, as discussed elsewhere over the past few years (33, $34,36)$. Doing more is recognizing that our systems are sociotechnical systems. Their maturity is our maturity, to be suitable and capable to move from "don't use and don't tell" and "if I don't look there is no problem" and "fail and fix" to be able to "predict and prevent" harm.

\section{REFERENCES}

1. Speedie MK. The impact of the national institute for pharmaceutical technology and education on academic research. AAPS PharmSciTech. 2018;19:2808-11. https://doi.org/10.1208/s12249018-1076-2 Accessed 24 Dec 2020.
2. Stamatis SD, Kirsch LE. Using manufacturing design space concepts for stability risk assessment-gabapentin NIPTE/FDA case study. AAPS PharmSciTech. 2018;19:2801-7. https:// doi.org/10.1208/s12249-018-1141-x Accessed 24 Dec 2020.

3. Ngeacharernkul P, Stamatis SD, Kirsch LE. Particle size distribution equivalency as novel predictors for bioequivalence. AAPS PharmSciTech. 2018;19:2787-800. https://doi.org/10.1208/ s12249-018-1121-1 Accessed 24 Dec 2020.

4. Shin SH, Srivilai J, Ibrahim SA, Strasinger C, Hammell DC, Hassan HE, et al. The sensitivity of in vitro permeation tests to chemical penetration enhancer concentration changes in fentanyl transdermal delivery systems. AAPS PharmSciTech. 2018;19:2778-86. https://doi.org/10.1208/s12249-018-1130-0 Accessed 24 Dec 2020.

5. Foo MY, Sawant N, Overholtzer E, Donovan MD. A simplified geometric model to predict nasal spray deposition in children and adults. AAPS PharmSciTech. 2018;19:2767-77. https:// doi.org/10.1208/s12249-018-1031-2 Accessed 24 Dec 2020.

6. Swaminathan SK, Fisher J, Kandimalla KK. Sensitive determination of fentanyl in low-volume serum samples by LC-MS/MS. AAPS PharmSciTech. 2018;19:2812-7. https://doi.org/10.1208/ s12249-018-1103-3 Accessed 24 Dec 2020.

7. Pikal MJ, Pande P, Bogner R, Sane P, Mudhivarthi V, Sharma P. Impact of natural variations in freeze-drying parameters on product temperature history: application of quasi steady-state heat and mass transfer and simple statistics. AAPS PharmSciTech. 2018;19:2828-42. https://doi.org/10.1208/s12249018-1155-4 Accessed 24 Dec 2020.

8. Haser A, Haight B, Berghaus A, Machado A, Martin C, Zhang F. Scale-up and in-line monitoring during continuous melt extrusion of an amorphous solid dispersion. AAPS PharmSciTech. 2018;19:2818-27. https://doi.org/10.1208/s12249018-1162-5 Accessed 24 Dec 2020.

9. Ferrati $\mathrm{S}, \mathrm{Wu} \mathrm{T}$, Fuentes $\mathrm{O}$, Brunaugh $\mathrm{AD}$, Kanapuram SR, Smyth HDC. Influence of formulation factors on the aerosol performance and stability of lysozyme powders: a systematic approach. AAPS PharmSciTech. 2018;19:2755-66. https:// doi.org/10.1208/s12249-018-0980-9 Accessed 24 Dec 2020.

10. Shah HS, Chaturvedi K, Hamad M, Bates S, Hussain A, Morris $\mathrm{K}$. New insights on solid-state changes in the levothyroxine sodium pentahydrate during dehydration and its relationship to chemical instability. AAPS PharmSciTech. 2019;20:39. https:// doi.org/10.1208/s12249-018-1264-0 Accessed 24 Dec 2020.

11. Lavan M, Byrn SR, Knipp G. Pediatric formulations: knowledge gaps limiting the expedited preclinical to clinical translation in children. AAPS PharmSciTech. 2019;20:73. https://doi.org/ 10.1208/s12249-018-1253-3 Accessed 24 Dec 2020.

12. Hussain AS, Gurvich VJ, Morris K. Pharmaceutical "new prior knowledge": twenty-first century assurance of therapeutic equivalence. AAPS PharmSciTech. 2019;20:140. https://doi.org/ 10.1208/s12249-019-1347-6 Accessed 24 Dec 2020.

13. Zhao Y, Drennen JK, Mohan S, Wu S, Anderson CA. Feedforward and feedback control of a pharmaceutical coating process. AAPS PharmSciTech. 2019;20:157. https://doi.org/ 10.1208/s12249-019-1348-5 Accessed 24 Dec 2020.

14. Charoo NA, Ali AA, Buha SK, Rahman Z. Lesson learnt from recall of valsartan and other angiotensin II receptor blocker drugs containing NDMA and NDEA impurities. AAPS PharmSciTech. 2019;20:166. https://doi.org/10.1208/s12249-0191376-1 Accessed 24 Dec 2020.

15. Byrn SR, Chen XS, Smith PA. Predictive and accelerated formulation design using synchrotron methods. AAPS PharmSciTech. 2019;20:176. https://doi.org/10.1208/s12249-0191375-2 Accessed 24 Dec 2020.

16. Bejarano A, Hewa Nadungodage C, Wang F, Catlin AC, Hoag SW. Decision support for excipient risk assessment in pharmaceutical manufacturing. AAPS PharmSciTech. 2019;20:223. https://doi.org/10.1208/s12249-019-1440-x Accessed 24 Dec 2020.

17. Swaminathan SK, Strasinger C, Kelchen M, Carr J, Ye W, Wokovich A, et al. Determination of rate and extent of scopolamine release from Transderm Scōp ${ }^{\circledR}$ transdermal drug delivery systems in healthy human adults. AAPS PharmSciTech. 2020;21:117. https://doi.org/10.1208/s12249-020-01658-4 Accessed 24 Dec 2020. 
18. Gurvich VJ, Hussain AS. In, and beyond COVID-19: US academic pharmaceutical science and engineering community must engage to meet critical national needs. AAPS PharmSciTech. 2020;21:153. https://doi.org/10.1208/s12249-02001718-9 Accessed 24 Dec 2020.

19. Shah HS, Sardhara R, Nahar K, Xu T, Delvadia P, Siddiqui A, et al. Development and validation of sample preparation and an HPLC analytical method for dissolution testing in fed-state simulated gastric fluid-illustrating its application for ibuprofen and ketoconazole immediate-release tablets. AAPS PharmSciTech. 2020;21:172. https://doi.org/10.1208/s12249-02001702-3 Accessed 24 Dec 2020.

20. Leuenberger H, Lanz M. Pharmaceutical powder technology - from art to science: the challenge of the FDA's process analytical technology initiative. Adv Powder Technol. 2005;16(1):3-25 https://sohailuniversity.edu.pk/wp-content/uploads/2018/12/Pharmaceutical-powder-technology-FDAsPAT.pdf.

21. Hussain AS. Viewpoint: the nation needs a comprehensive pharmaceutical engineering education and research system. Pharm Technol. 2005; http://alfresco.ubm-us.net/ alfresco_images/pharma/2014/08/22/fcb413f5-f60b-4316-a400c5e2f02cb9e8/article-178644.pdf. Accessed 19 Jan 2019.

22. NSF Engineering Research Centers. C-SOPs ERC for Structured Organic Particulate Systems. https://erc-assoc.org/content/ erc-structured-organic-particulate-systems. Accessed 24 Dec 2020.

23. 116th CONGRESS, 2D Session. H. R., 4866. "National Centers of Excellence in Continuous Pharmaceutical Manufacturing Act of 2020." IN THE SENATE OF THE UNITED STATES, 22 Sept 2020. https://www.congress.gov/bill/116th-congress/housebill/4866/text. Accessed 24 Dec 2020.

24. Hussain AS. NIPTE 2016: from roadblocks to roadmap-2017, with a 2020 vision. President's report. 2016. https://nipte.org/wpcontent/uploads/2018/10/Roadblocks-to-Roadmap-2017-with-A2020-Vision-12182016-Final-Version.pdf. Accessed 19 Jan 2019

25. Hussain AS. A collaborative search for efficient methods of ensuring unchanged product quality and performance during scale-up of immediate-release solid oral dosage forms. In: Levin M, editor. Pharmaceutical Process Scale-Up. 1st ed. Boca Raton: CRC Press; 2001.

26. US FDA. Center for drug evaluation and research. Scientific Public-Private Partnerships and Consortia. Find out how CDER works with partners and consortia to identify science gaps in drug development. Content current as of: 08/28/2020. https:// www.fda.gov/drugs/science-and-research-drugs/scientific-publicprivate-partnerships-and-consortia. Accessed 24 Dec 2020.

27. The National Institute for Pharmaceutical Technology and Education, Inc. (NIPTE) recommended topics for inclusion in the FY 2017 Regulatory Science Plan. 16 Jun 2016. Docket ID: FDA-2013-N-0402. Generic Drug User Fee Amendments of 2012; Regulatory Science Initiatives Part 15 Public Meeting, 2016 .

28. The National Institute for Pharmaceutical Technology and Education, Inc. (NIPTE) recommendations for planning FY
2019 GDUFA regulatory science initiatives. Submitted 24 Jun 2018 to Federal Register Docket FDA-2017-N-6644. https://www.regulations.gov/document?D=FDA-2017-N-66440004. Accessed 24 Dec 2020.

29. Wokovich AM, Prodduturi S, Doub WH, Hussain AS, Buhse LF. Transdermal drug delivery system (TDDS) adhesion as a critical safety, efficacy, and quality attribute. Eur J Pharm Biopharm. 2006 Aug;64(1):1-8. https://doi.org/10.1016/ j.ejpb.2006.03.009.

30. Crooker, P. A long and winding road for transdermal products FDA has it covered. regulatory update: FDA pathways for transdermal medical products. 12.11.19. https:// www.parexel.com/news-events-resources/blog/long-and-winding-road-transdermal-products-fda-has-it-covered. Accessed 24 Dec 2020.

31. Jamil R, Xu T, Shah SH, Adhikari A, Sardhara R, Nahar K, et al. Similarity of dissolution profiles from biorelevant media: assessment of inter-day repeatability, inter-analyst repeatability, and interlaboratory reproducibility using ibuprofen and ketoconazole tablets. Eur J Pharm Sci. 2021;156:105573, ISSN 09280987. https://doi.org/10.1016/j.ejps.2020.105573.

32. US FDA White paper: innovation and continuous improvement in pharmaceutical manufacturing: pharmaceutical CGMPs for the 21st century. The PAT team and manufacturing science working group report: a summary of learning, contributions, and proposed next steps for moving towards the "desired state" of pharmaceutical manufacturing in the 21st century. September 2004. https://wayback.archiveit.org/7993/20170405121836/https:// www.fda.gov/ohrms/dockets/ac/04/briefing/20044080b1_01_manufSciWP.pdf. Accessed 19 Jan 2019.

33. Hussain AS. How to break the pharmaceutical 2-3 sigma barrier (Like Amgen)? Pharmaceutical Online. Guest Column | 18 Sept 2017. https://www.pharmaceuticalonline.com/doc/how-tobreak-the-pharmaceutical-sigma-barrier-like-amgen-0001. Accessed 24 Dec 2020.

34. Hussain, AS. Chaos to Continual improvement: path to harmonization. CPhI Industry Report 2019: https:// www.cphi.com/content/dam/Informa/cphi/en/cphi-insights/ HLN19-CPhI\%20Insights-2019-Industry-Report.pdf. Accessed 24 Dec 2020.

35. Schondelmeyer SW. Impact of COVID-19 on drug shortages \& role of the resilient drug supply project. 2020 NIPTE Research Conference, 8 Dec 2020. For additional information on Resilient Drug Supply Project, see https://www.cidrap.umn.edu/rds. Accessed 24 Dec 2020.

36. Hussain, AS. Industry policy and NIPTE. 2020 NIPTE Research Conference, 8 Dec 2020. https://youtu.be/guVo1wQD7f0. Accessed 31 Dec 2020.

Publisher's Note Springer Nature remains neutral with regard to jurisdictional claims in published maps and institutional affiliations. 